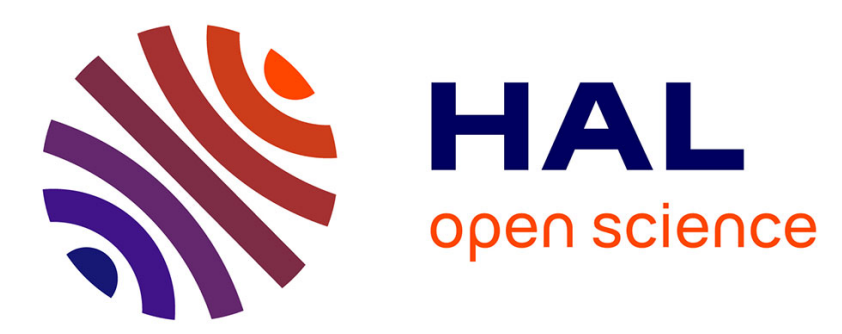

\title{
Transport and internal organization of membranes: vesicles, membrane networks and GTP-binding proteins
}

\author{
Jesus Ayala-Sanmartin
}

\section{To cite this version:}

Jesus Ayala-Sanmartin. Transport and internal organization of membranes: vesicles, membrane networks and GTP-binding proteins. Journal of Cell Science, 1994. hal-02562241

\section{HAL Id: hal-02562241 \\ https://hal.science/hal-02562241}

Submitted on 4 May 2020

HAL is a multi-disciplinary open access archive for the deposit and dissemination of scientific research documents, whether they are published or not. The documents may come from teaching and research institutions in France or abroad, or from public or private research centers.
L'archive ouverte pluridisciplinaire HAL, est destinée au dépôt et à la diffusion de documents scientifiques de niveau recherche, publiés ou non, émanant des établissements d'enseignement et de recherche français ou étrangers, des laboratoires publics ou privés. 


\title{
COMMENTARY
}

\section{Transport and internal organization of membranes: vesicles, membrane networks and GTP-binding proteins}

\author{
J. Ayala S. \\ CNRS URA 1414, Ecole Normale Supérieure, 46 rue d'Ulm, 75005 Paris, France
}

\section{INTRODUCTION}

Eukaryotic cells contain a variety of membranous organelles such as the Golgi complex and endosomes, which are organized to allow the flow of molecules to specific regions within the cell. Well known examples of this targeted flow include the transport of specific molecules to the apical pole of epithelial cells, to the axon terminals of neurons, and the transcytosis of immunoglobulins. The generally accepted model of transport between the different intracellular compartments maintains that transport is mediated by carrier vesicles, but recent data show the participation of tubulovesicular structures in membrane transport, and the assumed discontinuity of some intracellular compartments has come under considerable scrutiny. It seems that for different intracellular pathways, eukaryotic cells use both the vesicular and the tubular (bolus) means of transport. In this article I will discuss the vesicular and the tubular models of transport as well as a hypothesis for the mechanism of action of small GTPases of the rab family in these movements.

\section{THE VESICULAR MODEL}

The current model of transport describes vesicles as the fundamental carrier structures for the movement of elements between different compartments. Since the vesicular model has been the working hypothesis, only the more important aspects will be discused (Jamieson and Palade, 1967; Steinman et al., 1983; Pfeffer and Rothman, 1987; Rothman and Orci, 1992). In this model the organelles are physically isolated, a donor compartment produces vesicles, and these then move towards the acceptor membrane and fuse with it (Fig. 1A). This model includes a number of crucial steps that involve complex biological mechanisms, some of which are discussed below.

\section{Sorting: budding vesicles must possess an identity}

The specific contents of a vesicle are acquired by a mechanism that 'sorts' vesicle-associated molecules from the enormous repertoir of proteins present in the donor compartment. Thus, different proteins must be separated and transported to different vesicles with different contents and destinations (sorting), while the resident proteins stay in the donor organelles (retention). The sorting process can be explained by the aggregation of soluble species (passive) or by means of interaction with receptors (active mechanism) (Arvan and Castle, 1992).
One well studied sorting structure is the trans-Golgi network (TGN), where some of the various types of vesicles acquire their identity (secretory granules, constitutive vesicles, etc.) (Burgess and Kelly, 1987; Hashimoto et al., 1987; Sossin et al., 1990). One of the best characterized examples of sorting comes from the study of lysosomal enzymes (Kornfeld and Mellman, 1989). The sorting signal for these enzymes is a mannose-6-phosphate motif (Man-6-P). This group is recognized by a membrane associated Man-6-P receptor and the complex is selected to form the lysosomal enzyme-enriched vesicles.

This phosphorylation is not the only post-translational modification involved in the sorting mechanism, it also appears that the amino acid sequence of a protein can provide some of the sorting information. For example, the KDEL (one letter amino acid code) and related sequences have been shown to be important for the retention of luminal proteins in the endoplasmic reticulum (ER) (Munro and Pelham, 1987; Robbi and Beaufay, 1991). This retention might be mediated by "salvage receptors' that are apparently integral membrane proteins (Pelham, 1989; Lewis et al., 1990; Semenza et al., 1990; Warren, 1990). Another case is illustrated by the Golgi complex enzymes, $\beta$-1,4-galactosyltransferase and $\alpha$-2,6-sialyltransferase, whose retention signals seem to be mediated by their cytoplasmic N-terminal and membrane spanning domains (Munro, 1991; Nilsson et al., 1991; Russo et al., 1992; Teasdale et al., 1992).

In all these cases of sorting and retention, the cytoplasmic domain of the receptors must be recognized. Their association in a restricted zone forms patches or microdomains. The molecular mechanism of sorting could be the formation of homomolecular interactions at the level of the receptors themselves or heterocomplexes with coat proteins and adaptors, or some unknown matrices that separate resident from exported molecules (Simons and Wandinger-Ness, 1990). Indeed, the transferrin receptor and the cytoplasmic portion of the Man-6$\mathrm{P}$ receptors are recognized by different adaptors that are associated with the clathrin coats (Glickman et al., 1989; Smythe et al., 1992).

\section{Membrane domains}

The sorting problem leads us to a fundamental concept: a single (continuous) membrane must have regions from which

Key words: GTP-binding protein, vesicular transport, tubular transport 

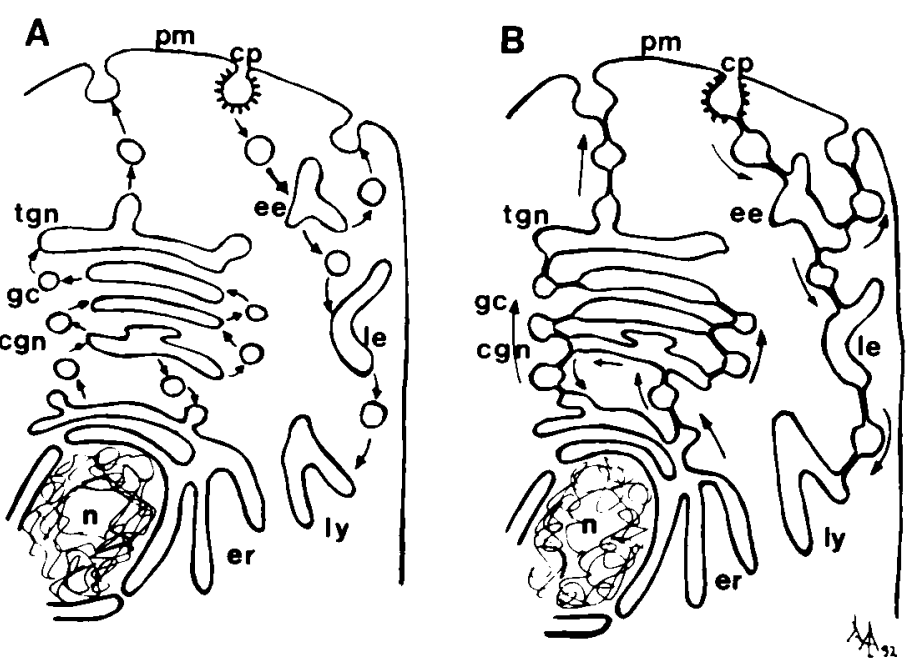

Fig. 1. (A) The all-vesicle-mediated intracellular transport model. All transport between organelles is mediated by vesicles. (B) The membrane network model. The organelles are actually a differentiated membrane network. Transport is carried out by the formation of a moving bolus (enlarged structures inside the tubules conecting the compartments). The eukaryotic cell may use both mechanisms, recruiting vesicle mediated transport when physiological isolation is required (see text and conclusions). $\mathrm{n}$, nucleus; er, endoplasmic reticulum; cgn, cis-Golgi network (intermediate/salvage compartment); gc, Golgi cisternae; tgn, transGolgi network; pm, plasma membrane; cp, coated pit; ee, early endosome; le, late endosome; ly, lysosome. The arrows represent the vectorial movements.

different vesicles are formed. In other words, one membrane must present specialized functional and structural domains composed of different proteins, and eventually lipids, that allow sorting and recycling of membrane molecules (Klumperman et al., 1993). The membrane domains could be pre-established by protein interactions with matrices or cytoskeletal elements (Edidin, 1992) or they could be transient structures formed at the moment of budding (Pearse and Robinson, 1990; Hopkins, 1992). No theory of membrane physiology can be proposed without this central concept of membrane heterogeneity, otherwise, to create the molecular and functional diversity of the organelles, molecules would have to be synthesized at their site of function.

\section{Budding and fission}

Coating proteins such as clathrin, Cops, adaptor proteins (adaptins) and ARFs (ADP-ribosylation factors) are involved in the formation of macromolecular complexes (Serafini et al., 1991a,b; Waters et al., 1991). In the case of clathrin, spherical lattices induce the curvature of membranes in formation of buds (Pearse and Bretscher, 1981; Pearse and Crowther, 1987; Lin et al., 1991). Then, for the fission of the vesicle, the energetics of hydrophobic-hydrophilic interactions must be taken into consideration. The need for ATP and GTP in in vitro fusion experiments may indicate an important energy source for fission to occur.

\section{Vesicle movement from one compartment to another}

A number of studies suggest that the directed movement of vesicles arises from the interactions of specific molecules at the vesicle surface with microtubules, microtubule-associated proteins or microfilaments. Thus, cytoskeletal elements could serve as 'rails' for the vesicles, while the energy required for movement could be furnished by motor proteins. Kinesin is considered as an anterograde (microtubule plus-end directed) motor, and dynein as a retrograde (minus-end directed) motor both of which associate with microtubules and membrane organelles (Schnapp and Reese, 1989; Schroer et al., 1989; Scheel and Kreis, 1991). Thus, such anterograde and retrograde motors could underlie the long distance centrifugal and centripetal transport of vesicles and lysosomes (Matteoni and Kreis, 1987; Hollenbeck and Swanson, 1990). In the case where donor and acceptor membranes are close to each other, these cytoskeletal interactions would not be necessary and the vesicles could 'diffuse' to reach their targets.

\section{Fusion}

The putative docking proteins and the cytoskeletal interactions are important for the directionality of transport. Once the vesicle is near the acceptor membrane, recognition of proteins on the surface of the vesicle and the target compartment might stabilize the membrane interactions for fusion to occur. This could be done by annexins and fusion machines (Beck et al., 1992; Creutz, 1992; Sztul et al., 1992; White, 1992; Söllner et al., 1993). In in vitro systems, pure phospholipid vesicles are believed to fuse in two steps. The first consists of the formation of a stable aggregate between membranes, driven by Van der Waals attraction. The second is probably the elimination of water, which would allow the hydrophobic contact and merging of the membranes. Removing the water from the polar heads of lipids is energetically costly. However, in some instances, lipid vesicles can fuse in vitro without the consumption of metabolic energy. In biological membranes the interaction of proteins could obviate this dehydration step, and the energy could be furnished by GTPases and ATPases to open a pore in the supposed docking/fusion complex (Monck and Fernandez, 1992; Curran et al., 1993).

\section{THE NATURE OF VESICLES}

In the vesicular model (Fig. 1A), vesicles are the central structure of intracellular transport. This model is mainly supported by electron microscopy studies that show vesicular structures in the cytoplasm, by the purification of transport vesicles and secretory granules, and by in vitro transport systems that have been used to characterize different transport pathways. In these in vitro systems, vesicles could even be purified (De Curtis and Simons, 1989; Malhotra et al., 1989).

\section{Microscopy}

Electron microscopy studies have revealed numerous vesicular elements in the cytoplasm of eukaryotic cells. However, a number of authors, have argued that many of the 'vesicles' in electron micrographs result from the section of tubular compartments such as endoplasmic reticulum, Golgi and endosomes, which were supposed to be continuous when seen in thick sections (Palade and Porter, 1954; Rambourg et al., 1979; Saraste and Kuismanen, 1984). To examine this directly, serial section reconstruction has been used to determine if a 
'vesicle' is a part of a tubular structure or if it exists as a separate unit. The thickness of the sections used in electron microscopy is an important factor for the interpretation of serial sectioning. The conclusion of these experiments is that the cytoplasm contains cisterna and tubules, as well as vesicles (Frokjaer-Jensen, 1980; Clough and Michel, 1981; Bundgaard et al., 1983). In some cases, the 'vesicles' can be the result of breakdown of thin membranes during various treatments and fixation making it difficult to measure the real number of vesicles in a cell and in general they are overestimated. Cryosectioning is another electron microscope technique that has the advantage of being very fast, avoids fixative treatment and has been shown to be very useful in studying the structure of organelles and of secretory vesicles and their putative pores.

\section{Transport in vitro}

Cell-free systems have been used to dissect transport mechanisms (Davis and Lazarus, 1976; Fries and Rothman, 1980; Balch et al., 1984; Gruenberg and Howell, 1989; Tooze and Huttner, 1990; Rexach and Schekman, 1991; Schwaninger et al., 1991). Some systems use semi-intact permeabilized cells to gain access to the transport machinery, while others use the membranes issued from one donor compartment that are mixed with membranes from an acceptor compartment. The transport is usually measured by means of the enzymatic modification of one protein when it reaches the lumen of the acceptor compartment or by detection of the formation of protein complexes (Gruenberg et al., 1989; Wessling-Resnick and Braell, 1990; Gorvel et al., 1991). These in vitro systems were used to characterize the action of drugs and the different factors involved in transport and exocytosis such as GTP, $\mathrm{Ca}^{2+}$, ATP and some cytosolic and membrane-associated proteins (Stutchfield and Cockcroft, 1988; Beckers and Balch, 1989; Beckers et al., 1989; Nadin et al., 1989; Pfanner et al., 1990; Wattenberg et al., 1990; Hiebsch et al., 1991). In all these in vitro experiments, the budding of the putative transport vesicles was found to require ATP and a mixture of proteins from the cytosol. ATP can even induce budding on the nuclear envelope, suggesting a new vesicular transport pathway between the nuclear membrane and other organelles (Hellgren and Morré, 1992; Morré et al., 1992), but at the same time the in vitro ATPinduced vesiculation must be taken into consideration.

Likely candidates for some of the specific proteins involved in fusion come from studies using peptides corresponding to different regions of rab and ARF proteins (small GTPases) or antibodies against many different proteins that partially or completely inhibit transport. The interpretation of in vitro experiments suggest that YPT1, NSF ( $N$-ethylmaleimidesensitive fusion protein), the NSF attachment proteins (SNAPs) and their receptors (SNAREs), form part of a docking or fusion complex between donor and acceptor compartments. It is quite possible that these proteins are members of a fusogenic complex (Segev, 1991; Balch et al., 1992; Wilson et al., 1992; Söllner et al., 1993).

The interpretations of in vitro experiments have been built upon the vesicular model, but they could also be interpreted in the context of tubular structure fusion, which occurs in the Golgi or endosomes in vivo in fused cells (Mellman and Simons, 1992). As I previously stated, the purification of in vitro vesicles is an argument to support their presence in living cells. This however was critizised by Morré et al. (1993) who proposed that in contrast with transition vesicles, clathrin coated vesicles or secretory vesicles, the buds of the intraGolgi apparatus are always associated with the isolated Golgi stacks, even under conditions optimized for interGolgi transfer, and they require harsh extraction methods for their preparation. This point of view was confirmed by experiments in which GTP $Y S$ uncoating reaction is accompanied with the formation of vesicles always attached to the cisternae (Weidman et al., 1993). Whether these in vitro vesicles are completely or partialy representative of in vivo phenomena, these systems are very useful to detect interactions between proteins (Balch, 1989; Wattenberg, 1990; D’Enfert et al., 1991a,b; Oka et al., 1991). As we shall see, some of these proteins could participate in the formation of protein complexes involved in the transport of a 'bolus' within tubular membrane structures.

\section{TUBULAR STRUCTURES AND TRANSPORT}

In addition to its role in supporting the vesicular model, the electron microscope has been used to reveal the existence of tubular structures in many different eukaryotic cells. The continuity of membrane structures such as the nuclear envelope and the ER, the ER and the dyctiosomes or the annulate lamellae is well known (Watson, 1955; Maul, 1970; Sitia and Meldolesi, 1992). The isolation of the stacks of the Golgi complex and the isolation of the Golgi from the ER and other organelles is becoming controversial (Novikoff and Novikoff, 1977; Broadwell and Cataldo, 1983; Rogalski et al., 1984; Cooper et al., 1990; Mellman and Simons, 1992; Rambourg et al., 1992; Clermont et al., 1993; Morré et al., 1993), and many groups have found tubular organelles associated with endocytic and exocytic pathways (McDowall et al., 1989; Rabinowitz et al., 1992). This data opens the possibility that in some of the intracellular transport pathways, movement is effected in tubular structures rather than by vesicles.

Moreover, cases exist in which the vesicular model has some difficulties in accounting for observed phenomena. During the exocytosis of neutrophil cells, alkaline phosphatase-positive rod-like elements fuse to form very long and large tubular secretory organelles, which associate with the plasma membrane (Kobayashi and Robinson, 1991). In these experiments, it was not possible to determine if the rod-like vesicles were actually the result of a tandem fusion of vesicular elements as a compound exocytosis, or if they were connected by thin fragile tubules susceptible to breakdown before the secretory stimulus. The presence of these tubules only after exocytosis may also be explained by their becoming enlarged (see below), and more resistant to fixative stress at the moment of exocytosis. Heuser (1989) showed reversible movements of tubular lysosomes depending on cytoplasmic $\mathrm{pH}$, but he also observed tubular lysosomes in low-pH-treated cells and some in non-treated (neutral $\mathrm{pH}$ ) cells. Similar results and the presence of tubular structures in lysosomes and late endosomes have been found in other experiments with epithelial cells, neurons and macrophages (Swanson et al., 1987; Parton et al., 1991).

It is true that tubular structures seen in these experiments could be interpreted as the result of fast fusion of vesicles or other membrane elements. However besides these static visualizations, Hopkins et al. (1990), published one of the most 
striking works to support tubular (bolus)-mediated transport in living cells. They observed an endosomal reticulum composed of tubular cisternae in which an endocytosed fluorescent marker revealed the presence of a bolus moving within a network of tubules. This work is particularly interesting because it eliminates possible membrane breakdown artifacts that can occur during fixation. In addition, the authors remark that fine tubules were very suceptible to breakdown (when exposed to UV, $\mathrm{pH}$ changes and 'low' temperatures $\left(20^{\circ} \mathrm{C}\right)$ ). This observation questions the vesicular nature of endosomal traffic.

\section{Brefeldin A}

Drugs that alter membrane traffic are useful for dissecting transport processes. Brefeldin A (BFA) inhibits the association of coating proteins ( $\beta$-Cop, ARF and $\gamma$-adaptin) with membranes (Donaldson et al., 1990, 1991; Pelham, 1991; Narula et al., 1992; Robinson and Kreis, 1992; Wong and Brodsky, 1992). BFA is able to alter different transport steps with the concommitant visualization of large tubular connections between different organelles (Lippincott-Schwartz et al., 1990; Hunziker et al., 1991; Wood et al., 1991; Tooze and Hollinshead, 1992). It was proposed that the uncoating caused by BFA inhibits the fission of a budding vesicle, provoking the extension of the bud, which fuses with the target compartment, making a tubular connection and facilitating mixture of the contents of the two compartments (Pelham, 1991; Klausner et al., 1992). The essential contradiction within this hypothesis is that we need to assume that membranes are competent to bud without any coat protein assembly (perhaps the only physiologically relevant effect of BFA), and in the classical view, the coating is necessary for budding. Another posibility is that BFA inhibits transport precisely by the uncoating of preexisting tubular connections, deregulating membrane traffic (see next sections). In fact, in the lysosomes, in which tubular structures are frequently seen (Heuser, 1989), BFA induces their 'formation', but when the drug is washed out, the 'new' tubules stay for long periods of time compared to other systems in which the reversibility of BFA effects is very fast (Lippincott-Schwartz et al., 1991). As we will see later, the enlargement of the proposed pre-existing tubular connections could be achieved by the action of BFA on coating proteins and their associated complexes. More recently Cluett et al. (1993) have demonstrated tubulation of Golgi cisternae by decreasing ATP levels in vivo and in vitro in conditions in which vesicle formation is also diminished.

\section{Cell fusion experiments}

One argument that favors the vesicular model occurs in fused cells. In these cells proteins can be transferred from one Golgi stack of one parental cell to the Golgi stack of a second cell, supporting that this requires the participation of vesicles (Rothman et al., 1984). This line of reasoning has recently been challenged (Mellman and Simons, 1992; Morré et al., 1993). Moreover, in cell fusion experiments with heterokaryons, transport from the ER to the Golgi is preferentially homologous rather than heterologous, implying that any vesicles involved in this step are not 'free' to diffuse in the cytoplasm (Valtersson et al., 1990). Supporting this view, De Curtis and Simons (1989) using an experimental system designed to isolate post-Golgi vesicles, could not find evidence for the release of transport vesicles derived from 'upstream' compartments such as the ER or intraGolgi. Therefore, either ER to Golgi transport vesicles are so close to their targets that they cannot diffuse, or these earlier transport steps are mediated by tubular networks.

In other studies in which soluble and resident proteins from the prelysosomal compartments of different parental cells were mixed, the organelles fused suggesting an affinity mediated perhaps by macromolecular complexes without the need for vesicular formation. The organelle resident proteins (that are apparently never found in vesicles) of the rat and mouse donor compartments (prelysosomes), are intermixed (Deng et al., 1991). In the vesicular model, these proteins are excluded from vesicles (retained) so they could not mix. Thus, in this case at least, the intermixing of the prelysosomal compartment is mediated by a pathway different from that suggested by the vesicular mechanism.

In conclusion, all those experiments did show tubular networks and cisternae in some endo and exocytic pathways, so the present models and the interpretations of transport experiments must account for these structures.

\section{THE MEMBRANE NETWORK MODEL}

An alternative transport model proposes the existence of a unique membrane network as shown in Fig. 1B, where the classic vesicles in Fig. 1A become a moving bolus within tubular membrane networks. Obviously, this is an exageration, and it is very probable that the cell uses vesicles as carriers in some pathways, but tubular transport is apparently also important in others. These latter cases (Hopkins et al., 1990), can be explained, so let us now consider the steps and the interpretation of available data.

\section{Heterogeneity of membrane networks}

We need to explain a regionalization of the membrane with segregation of proteins in different domains to form structural and functional heterogeneities (Sitia and Meldolesi, 1992). This point is not difficult to support if we accept the concept of membrane domains exactly as is expected for the sorting organelles like the TGN, the CGN (cis-Golgi network) and the endosomes in the vesicular model. This regional specialization can be explained in both models by interactions between different membrane proteins (coating proteins and adaptins) to separate retained from exported proteins.

\section{The model}

This model is essentially based on microscopical evidence of tubular structures, the effects of BFA, and the organelle behaviour in fused cells and endosomal traffic experiments demonstrated by Hopkins et al. (1990). We need to explain how the movement of membranes could be accomplished in membrane networks connecting functionally differentiated compartments. Fig. 2 illustrates how molecules can be moved in a continuous tubular structure. The closed tubule is enlarged forming a bolus of material by 'budding'. In fact, the mechanism of an enlarging tubule could be homologous to the mechanism proposed for a budding vesicle. Then the bolus translocates throughout the tubular membrane by the deforma- 

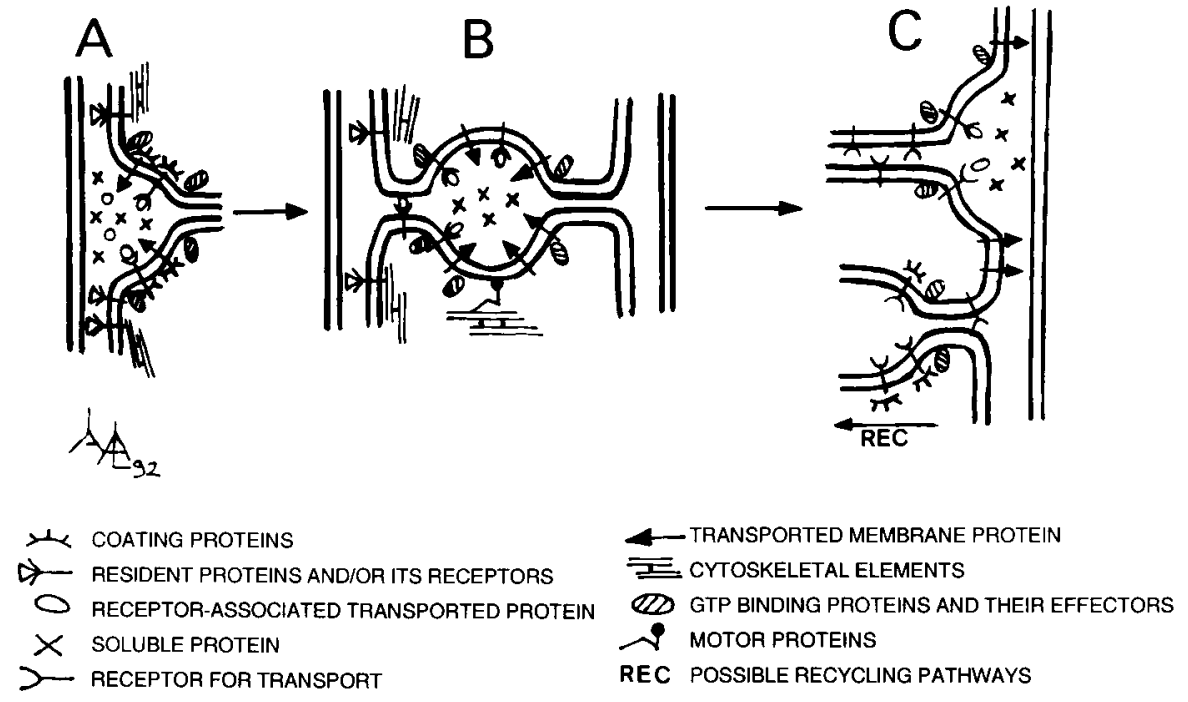

Fig. 2. Transport and recycling in the tubular network model. (A) The forming bolus could be explained by the same mechanism proposed for the budding vesicle. The coating proteins and adaptins may be involved in the curving of the membrane and in active sorting. (B) Once the bolus is formed, the proteins associated with membrane receptors and intrinsic membrane proteins can move given the fluidity of the lipid bilayer. The front and the rear of the bolus can open and close due to the formation and dissociation of molecular complexes (see Fig. 3 ). The bolus is isolated in this way precluding backward flow, difussion and the mixing of proteins in the connected compartments. The movement can be eventually assisted by motor proteins in association with the cytoskeleton. (C) The release of the contents of the bolus is a consequence of the mechanism shown in (B). The recycling of proteins could be achieved by backward movement of free receptors in a 'return tubular pathway'.

tion of the tubular wall creating a sort of wave that produces the flow (see Fig. 3).

The model can explain the bulk flow in the ER. This movement could be achieved by the formation of a bolus that directs the flow towards the Golgi region, like a 'peristaltic pump'. The vesicular aspect of the ER in optical microscopy could be due to the formation of boli, intervening in the transport to the Golgi complex. This mechanism could also explain the unknown bulk flow 'forces' and the sliding of bolus-like structures in the ER in characean algal cells (Kachar and Reese, 1988).

The steps and the requirements of the model are presented in the following paragraphs. It must be noted that many proteins and molecular interactions are essentially the same as those in the vesicular model, but it is simpler in the sense that the transport events do not require separate steps of fission and fusion.

\section{Retention, sorting and flow rate}

The selective mechanisms of molecular recognition of luminal proteins and retained receptors are the same as those proposed in the vesicular model. Coating proteins and adaptors could be involved in the formation of a 'budding' bolus, enriched in particular kinds of proteins.

Different membrane and secretory proteins exit the ER at distinct rates. Lodish et al. (1983) favored a model of proteins moving fast with the aid of receptors, and proteins moving slowly by bulk flow. A more plausible idea has been proposed by Pfeffer and Rothman (1987), which suggests that membrane association must retard the flux of proteins and the luminal elements migrate faster. This differential rate of export of proteins is explained in the bolus model due to the peristaltic pump-like movement. The created 'wave' makes the membrane-associated molecules move forward more slowly than the soluble material because the tubular movement is due to a change in the topology of the membrane (Fig. 2). The soluble proteins could be pushed by the bulk flow faster than some membrane intrinsic proteins that will form a part of an

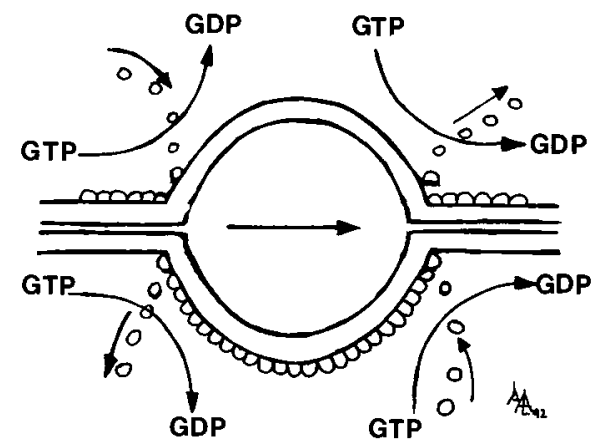

Fig. 3. GTP-binding proteins in tubular transport. The effectors of rab proteins could play a role in the formation and the dissociation of macromolecular complexes (coats) that change the topology of the membrane and in consequence effect the translocation of the bolus in the tubule (o-Macromolecular complexes).

'immobile phase', the movement of which depends mostly on the fluidity of the lipid bilayer. This mechanism could be the explanation of the serum albumin concentration in the ER during bulk flow (Mizuno and Singer, 1993). The retrograde transport observed in the intermediate compartment between the Golgi complex and the ER, and the recycling of proteins in general could be explained in the same way (Fig. 2C) (Lippincott-Schwartz et al., 1990; Saraste and Kuismanen, 1992).

\section{Directionality}

The membrane movements are directed towards a definite destination. In the vesicular model, the postulated docking and targetting molecules assure this specificity. This is not necessary in the tubular model, even if two compartments are connected by a tube, the tube is closed and bolus formation is achieved only in one of the compartments (Fig. 2). The cytoskeleton must be very important in the organization and distribution of the membrane organelles as is the case for the Golgi apparatus and lysosomes. The directionality of flow is then assured by 
the open/close mechanism. The closed tube in the rear of the bolus blocks both backward movement of soluble material and the mixing of the resident proteins of the donor and acceptor compartments. Only when we eliminate coating with BFA can we obtain the uncoating and opening of the tube and get mixing of the proteins of different compartments.

\section{Recycling}

The rate of endocytosis in different cells, as measured by pinocytosis, is variable (Steinman et al., 1983), but apparently a cell can internalize the equivalent of its cell surface in 0.5 to 2 hours. The measurements of bulk flow show that half of the phospholipids could leave the ER for the Golgi, two organelles with a very different surface area, in just 10 minutes (Wieland et al., 1987). This problem raises several questions regarding the recycling of membranes in exo and endocytotic processes. A cell cannot metabolize or resynthesize the membrane in such a short time, therefore, some type of recycling must be considered. As shown in Fig. 2 resident proteins and lipids would not be able to move out of the organelle because of some exclusion of the complex forming the bolus and/or by the attachment to the cytoskeleton or matrices. In fact, the lipidic matrix is more stationary than the soluble luminal portion of the bolus, and demands much less recycling than in the vesicular model. However, the recycling of other proteins and lipids (Koval and Pagano, 1989), could be achieved by flow in a retrograde pathway.

\section{Macromolecular complexes}

The importance of the multimeric complexes in membrane transport is becoming more clear as proteins such as the coatomers, clathrin, ARFs, and caveoline (Rothberg et al., 1992; Palmer et al., 1993) are shown to be involved in reversible processes of coating. Other macromolecular complexes may also participate in the stabilization and fusion of cisternae (Söllner et al., 1993). Most of the molecules involved in transport characterized to date are issued from in vitro transport systems, and some of them participate in vesicular fusion as is apparently the case for NSF, SNAPs and SNAREs. Others, such as rabs, are of unknown function.

\section{THE MECHANISM OF TRANSPORT AND THE GTP- BINDING PROTEINS}

GTP-binding proteins are involved in intracellular transport and secretion in different eukaryotes (Salminen and Novick, 1987; Goud et al., 1988; Bacon et al., 1989; Balch, 1990; Schwaninger et al., 1992; Taylor et al., 1992; Palme et al., 1993; Pimplikar and Simons, 1993). GTP hydrolysis seems to be necessary for transport in exocytic and endocytic pathways, since the non-hydrolyzable GTP analogue GTP $\gamma$ S inhibits transport at different steps of membrane traffic, vesicle uncoating, fusion, targeting and translocation (Melançon et al., 1987; Tooze et al., 1990). The action of GTP in transport in vivo and in vitro is sometimes mimicked by the $\mathrm{AlF}_{4}^{-}$, implying the action of trimeric GTP-binding proteins (Barr et al., 1991; Bomsel and Mostov, 1992; Leyte et al., 1992). Indeed, a trimeric GTP-binding protein appears to regulate the attachment of $\beta C$ op to the Golgi membranes, and thus antagonizes the effect of BFA (Ktistakis et al., 1992). Another set of GTP-binding proteins, the rab proteins, are localized in various membranous compartments. Rab4, rab5, rab7 and rab9 are associated with the endosomal compartments (Chavrier et al., 1990; Van der Sluijs et al., 1991; Lombardi et al., 1993). rab6 is present on the Golgi medial cisternae and the TGN (Goud et al., 1990; Antony et al., 1992), rab3 is primarily associated with synaptic vesicles and secretory granules (Darchen et al., 1990; Fischer von Mollard et al., 1990) and rab1 and rab2 are observed in the ER-Golgi region (Segev et al., 1988; Chavrier et al., 1990). Their presence in different compartments implicated in transport, coupled with genetic and in vitro transport data, strongly suggest that rab proteins play a fundamental role in membrane transport.

Various models of GTP-binding protein activity have been published by different authors (Bourne, 1988; Knight et al., 1989; Bourne et al., 1990; Goud and McCaffrey, 1991). The models must include the participation of different regulatory or effector proteins that interact with rabs such as the GTPase activating proteins (GAPs) (Burstein et al., 1991), GDP dissociation stimulators (GDS) also named guanine nucleotide releasing factors (GRFs) (Burstein and Macara, 1992; Moya et al., 1993) and GDP dissociation inhibitors (GDIs) (Sasaki et al., 1991). These proteins are believed to regulate the activeinactive conformational states of rabs and, at least for rab3 GDI, the cycling of the protein between membranes and cytoplasm (Araki et al., 1990; Fischer von Mollard et al., 1991; Regazzi et al., 1992).

The current model of rab protein function has been developed on the basis of the vesicular transport hypothesis. Briefly, it has been proposed that the GTP-binding protein associates with membranes and that GTP hydrolysis induces conformational changes in the protein involved in the signaling for vesicle budding, targeting (docking) or the fusion of the vesicle with the target membrane due to the interactions with effector proteins (Bourne, 1988; Goud and McCaffrey, 1991). Recently, rab3A was found to be associated with a synaptotagmin-like protein (Shirataki et al., 1992, 1993). The synaptotagmin in synaptic vesicles binds to membrane phospholipids and is supposed to participate in membrane fusion (Bommert et al., 1993). However, the nature and the precise role of effector proteins remains unknown.

\section{GTP-binding proteins and the membrane network model}

In both the vesicular and the network models a deformation of the membrane gives rise to a bud or a bolus. As discussed above, this most likely involves coating proteins. The inhibition of transport in vitro by GTP $\gamma \mathrm{S}$ that leads to an accumulation of coated vesicles (Melançon et al., 1987), suggests a role of GTP-binding proteins in the coating-uncoating process. Furthermore, it has been shown that mastoparan and the $\beta \gamma$ subunits of trimeric GTP-binding proteins inhibit the effect of GTPYS in an in vitro transport system (Colombo et al., 1992). In the tubular transport model one important step is the formation of a 'wave' that 'pushes' and/or 'pulls', in order to 'open' and/or 'close' the tubule and to allow the bolus to pass trough the tubule. This mechanism could be accomplished in part by GTP-binding proteins, which, acting in concert with other proteins to form coating complexes could allow changes in the topological characteristics of the membrane. For example, one candidate could be the small GTP-binding 
protein SAR1p that, in S. cerevisiae, interacts with SEC12 on the cytoplasmic face of the ER membrane to form complexes probably involved in 'budding' (D'Enfert et al., 1991a,b; Barlowe et al., 1993). Once the 'budding' is achieved, the interaction of the membrane with kinesin or dynein-like proteins or directly with actin filaments (Kachar and Reese, 1988) would result in energy-dependent vectorial movement (Fig. 2). As mentioned above, the fact that the BFA-induced tubulation and its effects on localization of adaptin-like molecules are blocked by pretreatment with GTP analogs could be explained by supposing that GTPases regulate the coating proteins in determining the thickness of tubules, and that their deregulation can produce large visible tubules more resistant to histochemical treatments.

\section{Are GTP-binding proteins involved in the formation of macromolecular complexes?}

As stated above, experiments with in vitro transport systems showed that GTP $\gamma$ S induces the accumulation of coated vesicles derived from Golgi stacks probably by the inhibition of the uncoating process. Other experiments showed that the preincubation of GTP $\gamma \mathrm{S}$ in vitro, blocks the BFA-induced dissociation of $\beta$-Cop (Orci et al., 1991). The GTP-binding protein ARF is involved in the association of the coatomer complexes (Serafini et al., 1991a; Donaldson et al., 1992a,b; Helms and Rothman, 1992), and is associated with clathrincoated vesicles (Lenhard et al., 1992). It seems that, not only can monomeric GTP-binding proteins participate in the formation of these coating complexes but also trimeric GTPbinding proteins seem to modulate the association of ARF and $\beta$-Cop to the Golgi (Donaldson et al., 1991).

One problem with the vesicular model is that YPT1 and rab1 appear to participate in budding, or in transport or even in fusion of vesicles in in vitro experiments (Plutner et al., 1991; Segev, 1991). These results seem paradoxical if these steps were so discrete, differentiated and specific as required by the vesicular hypothesis. Recently, it has been shown that different chimeric proteins containing different domains of SEC4 and YPT1 (yeast rab1), are able to complement SEC4 and YPT1 mutations, stating that the rabs are not acting as molecular tags to specify the acceptor compartment of a given vesicle (Brenwald and Novick, 1993; Dunn et al., 1993). This diversity of functions could be reflected in the diversity of this superfamily of proteins and even the various isoforms of individual proteins (rab1A, rab1B etc.). Another explanation is that in the case of tubular transport, the budding, transport, docking, and fusion could be seen just as different 'in-time-steps' of a moving bolus in which rab1 participates.

The specific role of rab proteins in transport steps is unknown. We can postulate that they could regulate the formation and dissociation of macromolecular complexes in the leading edge of the enlarging bolus or the constricting back of the tube in order to effect the movement of the bolus (Fig. 3 ). In both cases, a continuous change in the membrane topology provokes the 'wave' that translocates the bolus. In support of this hypothesis, it is interesting that the rab proteins are found associated with membranes and in the cytoplasm (Araki et al., 1990; Fischer von Mollard et al., 1991). It is believed that during their physiological function they are recycled between these two pools, as is the case for coating proteins. In this case we can predict that the rab effectors are some kind of coating molecules. Indeed, Weidman et al. (1993) found an increased abundance of tubules on primed versus unprimed Golgi membranes. These tubules are covered by a protein coat of unknown composition, but the authors suggest that it is different from clathrin, caveolin or coatomer coats. They may be formed by the tubulation factors suggested by Cluett et al. (1993).

\section{EVOLUTIONARY CONSIDERATIONS}

Resolving the question of the origin of internal membranes may help us to understand the mechanism of intracellular transport. The origin of mitochondria and chloroplasts is probably found in endosymbiotic processes. This is strongly supported by genetic studies and sequencing data. These organelles are apparently completely isolated from the general membrane transport pathways. However, given the different origin of chloroplasts and mitochondria from the Golgi, ER, lysosomes and the other internal membranes this is not so surprising. These latter organelles are likely to have arisen as a result of an invagination of the plasma membrane. The increase in the volume of the protoeukaryotic cells allowed the invagination of membranes in order to maintain a physiological volume-to-surface ratio. This may have led to the specialization of the internalized membranes to regulate communication with the environment. If this is the case, at least in the first stages of the protoeukaryotic life, the membranes could have been interconnected and probably attached to the plasma membrane in a similar way to the tubular model represented in Fig. 1B. Later, the differentiation of functions has led to a separation of some membranes of the network, like the plasma membrane, to assure isolation from the environment and from some agressive compartments such as the low $\mathrm{pH}$ and proteaseenriched lysosomes and others like the stockage specialized compartments $\left(\mathrm{Ca}^{2+}\right.$, vacuoles etc.). Evolution could have lead to the utilisation of different mechanisms of transport in different cases: in some steps vesicles may have been selected, whereas in others the bolus may be more efficient. However, the mechanisms and the intervening molecules may be very similar.

\section{CONCLUSIONS}

(1) Vesicles are considered as the general vehicles for intracellular transport but recent data show the existence of tubular transport in living cells in steps that were thought to be mediated by vesicles (i.e. the endocytic pathway). Moreover, tubular structures are shown to be associated with the exocytic and endocytic pathways.

(2) The tubular and vesicular models discussed above have their advantages and weaknesses. The tubular network model is mainly supported by: (a) electron microscopy evidence; (b) BFA effects; (c) heterocaryon cell fusion experiments; and (d) the observed bolus movement in living cells in the endocytic pathway. Even if it is not possible to account for all transport events via a single membrane, tubular networks are becoming more evident and deserve more attention. It is possible that both mechanisms take place in the cell and that some isolated organelles need to communicate through vesicles e.g. the plasma membrane, storage compartments such as secretory 
granules, vacuoles or the enzyme aggressive lysosomes. Other traffic pathways are probably mediated by means of a bolus in tubular conections as is apparently the case for early to late endosomes and Golgi to ER retrograde transport.

(3) GTP-binding proteins are localized in almost all membranes inside the cell. The proposed interactions of rab proteins with their regulators in this article, are the same as those proposed by other authors, but their action is not only envisaged in terms of fission, budding or transport of vesicles but also for tubular transport. Rab proteins and other GTPbinding proteins could participate in the transport processes by regulating the association of protein complexes that produce changes in the topology of membranes either in vesicular or in bolus movements.

I thank M. Bornens, E. Hetier, D. Karagogeos, K. Moya, A. Prochiantz, A. Tixier-Vidal and, especially, B. Goud, for stimulating discussions and constructive criticism of the models.

\section{REFERENCES}

Antony, C., Cibert, C., Géraud, G., Santa Maria, A., Maro, B., Mayau, V. and Goud, B. (1992). The small GTP-binding protein rab6p is distributed from medial Golgi to the trans-Golgi network as determined by a confocal microscopic approach. J. Cell Sci. 103, 785-796.

Araki, S., Kikuchi, A., Hata, Y., Isomura, M. and Takai, Y. (1990). Regulation of reversible binding of smgp25A, a rasp21-like GTP-binding protein to synaptic plasma membranes and vesicles by its specific regulatory protein, GDP dissociation inhibitor. J. Biol. Chem. 265, 13007-13015.

Arvan, P. and Castle, D. (1992). Protein sorting and secretion granule formation in regulated secretory cells. Trends Cell Biol. 2, 327-331.

Bacon, R. A., Salminen, A., Ruohola, H., Novick, P. and Ferro-Novick, S. (1989). The GTP-binding protein YPT1 is required for transport in vitro: The Golgi apparatus is deffective in ypt1 mutants. J. Cell Biol. 109, 1015-1022.

Balch, W. E., Dunphy, W. G., Braell, W. A. and Rothman, J. E. (1984). Reconstitution of the transport of protein between successive compartments of the Golgi measured by the coupled incorporation of $\mathrm{N}$-acetylglucosamine. Cell 39, 405-416.

Balch, W. E. (1989). Biochemistry of interorganelle transport. A new frontier in enzymology emerges from versatile in vitro model systems. J. Biol. Chem. 264, 16965-16968.

Balch, W. E. (1990). Small GTP-binding proteins in vesicular transport. Trends Biochem. Sci. 15, 473-477.

Balch, W. E., Kahn, R. A. and Schwaninger, R. (1992). ADP-ribosylation factor is required for vesicular trafficking between the endoplasmic reticulum and the cis-Golgi compartment. J. Biol. Chem. 267, 13053-13061.

Barlowe, C., D'Enfert, C. and Schekman, R. (1993). Purification and characterization of SAR1p, a small GTP-binding protein required for transport vesicle formation from the endoplasmic reticulum. J. Biol. Chem. 268, 873-879.

Barr, F. A., Leyte, A., Mollner, S., Pfeuffer, T., Tooze, S. A. and Huttner, W. B. (1991). Trimeric G-proteins of the trans-Golgi network are involved in the formation of constitutive secretory vesicles and immature secretory granules. FEBS Lett. 294, 239-243.

Beck, K. A., Chang, M., Brodsky, F. M. and Keen, J. H. (1992). Clathrin assembly protein AP-2 induces aggregation of membrane vesicles: A possible role for AP-2 in endosome formation. J. Cell Biol. 119, 787-796.

Beckers, C. J. M. and Balch, W. E. (1989). Calcium and GTP: Essential components in vesicular trafficking between the endoplasmic reticulum and Golgi apparatus. J. Cell Biol. 108, 1245-1256.

Beckers, C. J. M., Block, M. R., Glick, B. S., Rothman, J. E. and Balch, W. E. (1989). Vesicular transport between the endoplasmic reticulum and the Golgi stack requires the NEM-sensitive fusion protein. Nature 339, 397-398.

Bommert, K., Charlton, M. P., DeBello, W. M., Chin, G. J., Betz, H. and Augustine, G. J. (1993). Inhibition of neurotransmitter release by C2domain peptides implicates synaptotagmin in exocytosis. Nature 363, 163165 .

Bomsel, M. and Mostov, K. (1992). Role of heterotrimeric G proteins in membrane traffic. Mol. Biol. Cell 3, 1317-1328.
Bourne, H. R. (1988). Do GTPases direct membrane traffic in secretion? Cell 53, 669-671.

Bourne, H. R., Sanders, D. A. and McCormick, F. (1990). The GTPase superfamily: a conserved switch for diverse cell functions. Nature 348, 125132.

Brenwald, P. and Novick, P. (1993). Interactions of three domains distinguishing the ras-related GTP-binding proteins Ypt1 and Sec4. Nature 362, 560-563.

Broadwell, R. D. and Cataldo, A. M. (1983). The neuronal endoplasmic reticulum: Its cytochemistry and contribution to the endomembrane system. I. Cell bodies and dendrites. J. Histochem. Cytochem. 31, 1077-1088.

Bundgaard, M., Hagman, P. and Crone, C. (1983). The three-dimensional organization of plasmalemmal vesicular profiles in the endothelium of rat heart capillaries. Microvasc. Res. 25, 358-368.

Burgess, T. L. and Kelly, R. B. (1987). Constitutive and regulated secretion of proteins. Annu. Rev. Cell Biol. 3, 243-293.

Burstein, E. S., Linko-Stentz, K., Lu, Z. and Macara, I. G. (1991). Regulation of the GTPase activity of the ras-like protein p25rab3A. Evidence for a rab3A-specific GAP. J. Biol. Chem. 266, 2689-2682.

Burstein, E. S. and Macara, I. G. (1992). Characterization of a guanine nucleotide-releasing factor and a GTPase-activating protein that are specific for the ras-related protein p25rab3A. Proc. Nat. Acad. Sci. USA 89, 11541158 .

Chavrier, P., Parton, R. G., Hauri, H. H., Simons, K. and Zerial, M. (1990). Localization of low molecular weight GTP-binding proteins to exocytic and endocytic compartments. Cell 62, 317-329.

Clermont, Y., Xia, L., Rambourg, A., Turner, J. D. and Hermo, L. (1993). Transport of casein submicelles and formation of secretion granules in the Golgi apparatus of epithelial cells of the lactating mammary gland of the rat. Anat. Rec. 235, 363-373.

Clough, G. and Michel, C. C. (1981). The role of vesicles in the transport of ferritin through frog endothelium. J. Physiol. 315, 127-142.

Cluett, E. B., Wood, S. A., Banta, M. and Brown, W. J. (1993). Tubulation of Golgi membranes in vivo and in vitro in the absence of Brefeldin A. J. Cell Biol. 120, 15-24.

Colombo, M. I., Mayorga, L. S., Casey, P. J. and Stahl, P. D. (1992). Evidence of a role for heterotrimeric GTP-binding proteins in endosome fusion. Science 255, 1695-1697.

Cooper, M. S., Cornell-Bell, A. H., Chernajavsky, A., Dani, J. W. and Smith, S. J. (1990). Tubulovesicular processes emerge from trans-Golgi cisternae, extend along microtubules, and interlink adjacent trans-Golgi elements into a reticulum. Cell 61, 135-145.

Creutz, C. E. (1992). The annexins and exocytosis. Science 258, 924-931.

Curran, M. J., Cohen, F. S., Chandler, D. E., Munson, P. J. and Zimmerberg, J. (1993). Exocytotic fusion pores exhibit semi-stable states. J. Membr. Biol. 133, 61-75.

D'Enfert, C., Barlowe, C., Nishikawa, S., Nakano, A. and Schekman, R. (1991a). Structural and functional dissection of a membrane glycoprotein required for vesicle budding from the endoplasmic reticulum. Mol. Cell. Biol. 11, 5727-5734.

D'Enfert, C., Wuestehube, L. J., Lila, T. and Schekman, R. (1991b). SEC12p-dependent membrane binding of the small GTP-binding protein Sar1p promotes formation of transport vesicles from the ER. J. Cell Biol. 114, 663-670.

Darchen, F., Zahraoui, A., Hammel, F., Monteils, M.-P., Tavitian, A. and Scherman, D. (1990). Association of the GTP-binding protein rab3A with bovine adrenal chromaffin granules. Proc. Nat. Acad. Sci. USA 87, 5692-5696.

Davis, B. and Lazarus, N. R. (1976). An in vitro system for studying insulin release caused by secretory granules-plasma membrane interaction: definition of the system. J. Physiol. 256, 709-729.

De Curtis, I. and Simons, K. (1989). Isolation of exocytic carrier vesicles from BHK cells. Cell 58, 719-727.

Deng, Y., Griffiths, G. and Storrie, B. (1991). Comparative behavior of lysosomes and the pre-lysosome compartment (PLC) in in vivo cell fusion experiments. J. Cell Sci. 99, 571-582.

Donaldson, J. G., Lippincott-Schwartz, J., Bloom, G. S., Kreis, T. E. and Klausner, R. D. (1990). Dissociation of a $110 \mathrm{kD}$ peripheral membrane protein from the Golgi apparatus is an early event in brefeldin A action. $J$. Cell Biol. 111, 2295-2306.

Donaldson, J. G., Kahn, R. A., Lippincott-Schwartz, J. and Klausner, R. D. (1991). Binding of ARF and $\beta C o p$ to Golgi membranes: possible regulation by a trimeric G protein. Science 254, 1197-1199.

Donaldson, J. G., Cassel, D., Kahn, R. A. and Klausner, R. D. (1992a). ADP-ribosylation factor, a small GTP-binding protein, is required for 
binding of the coatomer protein $\beta$-COP to Golgi membranes. Proc. Nat. Acad. Sci. USA 89, 6408-6412.

Donaldson, J. G., Finazzi, D. and Klausner, R. D. (1992b). Brefeldin A inhibits Golgi membrane-catalysed exchange of guanine nucleotide onto ARF protein. Nature 360, 350-352.

Dunn, B., Stearns, T. and Botstein, D. (1993). Specificity domains distinguish the ras-related GTPases Ypt1 and Sec4. Nature 362, 563-565.

Edidin, M. (1992). Patches, posts and fences: proteins and plasma membrane domains. Trends Cell Biol. 2, 376-380.

Fischer von Mollard, G., Mignery, G. A., Baumert, M., Perin, M. S., Hanson, T. J., Burger, P. M., Jahn, R. and Südhof, T. C. (1990). rab3 is a small GTP-binding protein exclusively localized to synaptic vesicles. Proc. Nat. Acad. Sci. USA 87, 1988-1992.

Fischer von Mollard, G., Südhof, T. C. and Jahn, R. (1991). A small GTPbinding protein dissociates from synaptic vesicles during exocytosis. Nature 349, 79-81.

Fries, E. and Rothman, J. E. (1980). Transport of vesicular stomatitis virus glycoprotein in a cell-free extract. Proc. Nat. Acad. Sci. USA 77, 3870-3874.

Frokjaer-Jensen, J. (1980). Three dimensional organization of plasmalemmal vesicles in endothelial cells. An analysis by serial sectioning of frog mesenteric capillaries. J. Ultrastruct. Res. 73, 9-20.

Glickman, J. N., Conibear, E. and Pearse, B. M. F. (1989). Specificity of binding of clathrin adaptors to signals on the mannose-6-phosphate/insulinlike growth factor II receptor. EMBO J. 8, 1041-1047.

Gorvel, J. P., Chavrier, P., Zerial, M. and Gruenberg, J. (1991). Rab5 controls early endosome fusion in vitro. Cell 64, 915-925.

Goud, B., Salminen, A., Walworth, N. C. and Novick, P. F. (1988). A GTPbinding protein required for secretion rapidly associates with secretory vesicles and the plasma membrane in yeast. Cell 53, 753-768.

Goud, B., Zahraoui, A., Tavitian, A. and Saraste, J. (1990). Small GTPbinding protein associated with Golgi cisternae. Nature 345, 553-556.

Goud, B. and McCaffrey, M. (1991). Small GTP-binding proteins and their role in transport. Curr. Opin. Cell Biol. 3, 626-633.

Gruenberg, J., Griffiths, G. and Howell, K. E. (1989). Characterization of the early endosome and putative endocytic carrier vesicles in vivo and with an assay of vesicle fusion in vitro. J. Cell Biol. 108, 1301-1316.

Gruenberg, J. and Howell, K. E. (1989). Membrane traffic in endocytosis: insights from cell-free assays. Annu. Rev. Cell Biol. 5, 453-481.

Hashimoto, S., Fumagalli, G., Zanini, A. and Meldolesi, J. (1987). Sorting of three secretory proteins to distinct secretory granules in acidophilic cells of cow anterior pituitary. J. Cell Biol. 105, 1579-1586.

Hellgren, L. and Morré, D. J. (1992). ATP-induced budding of nuclear envelope in vitro. Protoplasma 167, 238-242.

Helms, J. B. and Rothman, J. E. (1992). Inhibition by brefeldin A of a Golgi membrane enzyme that catalyses exchange of guanine nucleotide bound to ARF. Nature 360, 352-354.

Heuser, J. (1989). Changes in lysosome shape and distribution correlated with changes in cytoplasmic pH. J. Cell Biol. 108, 855-864.

Hiebsch, R. R., Raub, T. J. and Wattemberg, B. W. (1991). Primaquine blocks transport by inhibiting the formation of functional transport vesicles. Studies in a cell-free assay of protein transport through the Golgi apparatus. J. Biol. Chem. 266, 20323-20328.

Hollenbeck, P. J. and Swanson, J. A. (1990). Radial extension of macrophage tubular lysosomes supported by kinesin. Nature 346, 864-866.

Hopkins, C. R., Gibson, A., Shipman, M. and Miller, K. (1990). Movement of internalized ligand-receptor complexes along a continuous endosomal reticulum. Nature 346, 335-339.

Hopkins, C. R. (1992). Selective membrane protein trafficking: vectorial flow and filter. Trends Biochem. Sci. 17, 27-32.

Hunziker, W., Whitney, J. A. and Mellman, I. (1991). Selective inhibition of transcytosis by brefeldin A in MDCK cells. Cell 67, 617-627.

Jamieson, J. D. and Palade, G. E. (1967). Intracellular transport of secretory proteins in the pancreatic exocrine cell. I. Role of the peripheral elements of the Golgi complex. J. Cell Biol. 34, 577-596.

Kachar, B. and Reese, T. S. (1988). The mechanism of cytoplasmic streaming in characean algal cells: sliding of endoplasmic reticulum along actin filaments. J. Cell Biol. 106, 1545-1552.

Klausner, R. D., Donaldson, J. G. and Lippincott-Schwartz, J. (1992). Brefeldin A: Insights into the control of membrane traffic and organelle structure. J. Cell Biol. 116, 1071-1080.

Klumperman, J., Hille, A., Veenendaal, T., Oorschot, V., Stoorvogel, W, Von Figura, K. and Geuze, H. J. (1993). Differences in the endosomal distributions of the two mannose 6-phosphate receptors. J. Cell Biol. 121, 997-1010.
Knight, D. E., Von Grafenstein, H. and Athayde, C. M. (1989). Calciumdependent and calcium-independent exocytosis. Trends Neurosci. 12, 451-458.

Kobayashi, T. and Robinson, J. M. (1991). A novel intracellular compartment with unusual secretory properties in human neutrophils. J. Cell Biol. 113, 743-756.

Kornfeld, S. and Mellman, I. (1989). The biogenesis of lysosomes. Annu. Rev. Cell Biol. 5, 483-525.

Koval, M. and Pagano, R. E. (1989). Lipid recycling between the plasma membrane and intracellular compartments: Transport and metabolism of fluorescent sphingomyelin analogues in cultured fibroblasts. J. Cell Biol. 108, 2169-2181.

Ktistakis, N. T., Linder, M. E. and Roth, M. G. (1992). Action of brefeldin A blocked by activation of a pertussis-toxin-sensitive G protein. Nature 356, 344-346.

Lenhard, J. M., Kahn, R. A. and Stahl, P. D. (1992). Evidence for ADPribosylation factor (ARF) as a regulator of in vitro endosome-endosome fusion. J. Biol. Chem. 267, 13047-13052.

Lewis, M. J., Sweet, D. J. and Pelham, H. R. (1990). The ERD2 gene determines the specificity of the luminal ER protein retention system. Cell 61, 1359-1363.

Leyte, A., Barr, F. A., Kehlenbach, R. H. and Huttner, W. B. (1992). Multiple trimeric G-proteins on the trans-Golgi network exert stimulatory and inhibitory effects on secretory vesicle formation. EMBO J. 11, 4795-4804.

Lin, H. C., Moore, M. S., Sanan, D. A. and Anderson, R. G. W. (1991). Reconstitution of clathrin-coated pit budding from plasma membranes. $J$. Cell Biol. 114, 881-891.

Lippincott-Schwartz, J., Donaldson, J. G., Schweizer, A., Berger, E. G., Hauri, H., Yuan, L. C. and Klausner, R. D. (1990). Microtubuledependent retrograde transport of proteins into the ER in the presence of brefeldin A suggests an ER recycling pathway. Cell 60, 821-836.

Lippincott-Schwartz, J., Yuan, L., Tipper, C., Amherdt, M., Orci, L. and Klausner, R. D. (1991). Brefeldin A's effects on endosomes, lysosomes, and the TGN suggest a general mechanism for regulating organelle structure and membrane traffic. Cell 67, 601-616.

Lodish, H. F., Kong, N., Snider, M. and Strous, G. J. A. M. (1983). Hepatoma secretory proteins migrate from rough endoplasmic reticulum to Golgi at characteristic rates. Nature 304, 80-83.

Lombardi, D., Soldati, T., Riederer, M. A., Goda, Y., Zerial, M. and Pfeffer, S. R. (1993). Rab9 functions in transport between late endosomes and the trans Golgi network. EMBO J. 12, 677-682.

Malhotra, V., Serafini, T., Orci, L., Shepherd, J. C. and Rothman, J. E. (1989). Purification of a novel class of coated vesicles mediating biosynthetic protein transport through the Golgi stack. Cell 58, 329-336.

Matteoni, R. and Kreis, T. E. (1987). Translocation and clustering of endosomes and lysosomes depends on microtubules. J. Cell Biol. 105, 12531265.

Maul, G. G. (1970). On the relationship between the Golgi apparatus and the annulate lamellae. J. Ultrastruct. Res. 30, 368-384.

McDowall, A., Gruenberg, J., Römisch, K. and Griffiths, G. (1989). The structure of organelles of the endocytic pathway in hydrated cryosections of cultured cells. Eur. J. Cell Biol. 49, 281-294.

Melançon, P., Glick, B. S., Malhotra, V., Weidman, P. J., Serafini, T., Gleason, M. L., Orci, L. and Rothman, J. E. (1987). Involvement of GTPbinding ' $G$ ' proteins in transport through the Golgi stack. Cell 51, 1053-1062.

Mellman, I. and Simons, K. (1992). The Golgi complex: in vitro veritas? Cell 68, 829-840.

Mizuno, M. and Singer, S. J. (1993). A soluble secretory protein is first concentrated in the endoplasmic reticulum before transfer to the Golgi apparatus. Proc. Nat. Acad. Sci. USA 90, 5732-5736.

Monck, J. R. and Fernandez, J. M. (1992). The exocytotic fusion pore. J. Cell Biol. 119, 1395-1404.

Morré, D. J., Penel, C., Morré, D. M., Hellgren, L., Sandelius, A. S. and Greppin, H. (1992). ATP-dependent cell-free transfer of membrane lipids from nuclei to Golgi apparatus of germinating axes of garden pea. Protoplasma 170, 1-9.

Morré, D. J., Keenan, T. W. and Morré, D. M. (1993). Golgi apparatus isolation and use in cell-free systems. Protoplasma 172, 12-26.

Moya, M., Roberts, D. and Novick, P. (1993). DSS4-1 is a dominant suppressor of sec4-8 that encodes a nucleotide exchange protein that aids Sec4p function. Nature 361, 460-463.

Munro, S. and Pelham, H. R. B. (1987). A C-terminal signal prevents secretion of luminal ER proteins. Cell 48, 899-907.

Munro, S. (1991). Sequences within and adjacent to the transmembrane 
segment of $\alpha-2,6$-sialyltransferase specify Golgi retention. EMBO J. 10, 3577-3588

Nadin, C. Y., Rogers, J., Tomlinson, S. and Edwardson, M. J. (1989). A specific interaction in vitro between pancreatic zymogen granules and plasma membranes: Stimulation by G-protein activators but not by $\mathrm{Ca}^{2+} . J$. Cell Biol. 109, 2801-2808.

Narula, N., McMorrow, I., Plopper, G., Doherty, J., Matlin, K. S., Burke, B. and Stow, J. L. (1992). Identification of a $200-\mathrm{kD}$, brefeldin-sensitive protein on Golgi membranes. J. Cell Biol. 117, 27-38.

Nilsson, T., Lucocq, J. M., Mackay, D. and Warren, G. (1991). The membrane spanning domain of $\beta$-1, 4-galactosyl transferase specifies trans Golgi localization. EMBO J. 10, 3567-3575.

Novikoff, A. B. and Novikoff, P. M. (1977). Cytochemical contributions to differentiating GERL from the Golgi apparatus. Histochemical J. 9, 525-551.

Oka, T., Nishikawa, S. and Nakano, A. (1991). Reconstitution of GTP-binding Sar1 protein function in ER to Golgi transport. J. Cell Biol. 114, 671-679.

Orci, L., Tagaya, M., Amherdt, M., Perrelet, A., Donaldson, J. G., Lippincot-Schwartz, J., Klausner, R. D. and Rothman, J. E. (1991). Brefeldin A, a drug that blocks secretion, prevents the assembly of non clathrin-coated buds on Golgi cisternae. Cell 64, 1183-1195.

Palade, G. E. and Porter, K. R. (1954). Studies on the endoplasmic reticulum. I. Its identification in cells in situ. J. Exp. Med. 100, 641-656.

Palme, K., Diefenthal, T. and Moore, I. (1993). The ypt gene family from maize and Arabidopsis: structural and functional analysis. J. Exp. Botany 44, 183-195.

Palmer, D. J., Helms, J. B., Beckers, C. J. M., Orci, L. and Rothman, J. E. (1993). Binding of coatomer to Golgi membranes requires ADP-ribosylation factor. J. Biol. Chem. 268, 12083-12089.

Parton, R. G., Dotti, G. C., Bacallao, R., Kurtz, I., Simons, K. and Prydz, K. (1991). pH-induced microtubule-dependent redistribution of late endosomes in neuronal and epithelial cells. J. Cell Biol. 113, 261-274.

Pearse, B. M. F. and Bretscher, M. S. (1981). Membrane recycling by coated vesicles. Annu. Rev. Biochem. 50, 85-101.

Pearse, B. M. F. and Crowther, R. A. (1987), Structure and assembly of coated vesicles. Annu. Rev. Biophys. Biophys. Chem. 16, 49-68.

Pearse, B. M. F. and Robinson, M. S. (1990). Clathrin, adaptors and sorting. Annu. Rev. Cell Biol. 6, 151-171.

Pelham, H. R. B. (1989). Control of protein exit from the endoplasmic reticulum. Annu. Rev. Cell Biol. 5, 1-23.

Pelham, H. R. B. (1991). Multiple targets for brefeldin A. Cell 67, 449-451.

Pfanner, N., Glick, B. S., Arden, S. R. and Rothman, J. E. (1990). Fatty acylation promotes fusion of transport vesicles with Golgi cisternae. J. Cell Biol. 110, 955-961.

Pfeffer, S. R. and Rothman, J. E. (1987). Biosynthetic protein transport and sorting by the endoplasmic reticulum and Golgi. Annu. Rev. Biochem. 56, 829-852.

Pimplikar, S. W. and Simons, K. (1993). Regulation of apical transport in epithelial cells by $\mathrm{a}_{\mathrm{s}}$ class of heterotrimeric $\mathrm{G}$ protein. Nature $\mathbf{3 6 2}, 456-458$.

Plutner, H., Cox, A. D., Pind, S., Khosravi-Far, R., Bourne, J. R., Schwaninger, R., Der, C. J. and Balch, W. E. (1991). Rab1b regulates vesicular transport between the endoplasmic reticulum and successive Golgi compartments. J. Cell Biol. 115, 31-43.

Rabinowitz, S., Horstmann, H., Gordon, S. and Griffiths, G. (1992). Immunocytochemical characterization of the endocytic and phagolysosomal compartments in peritoneal macrophages. J. Cell Biol. 116, 95-112.

Rambourg, A., Clermont, Y. and Hermo, L. (1979). Three-dimensional architecture of the Golgi apparatus in Sertoli cells of the rat. Amer. J. Anat. 154, $455-476$

Rambourg, A., Clermont, Y., Chretien, M. and Olivier, L. (1992). Formation of secretory granules in the Golgi apparatus of prolactin cells in rat pituitary gland: a stereoscopic study. Anat. Rec. 232, 169-179.

Regazzi, R., Kikuchi, A., Takai, Y. and Wollheim, C. B. (1992). The small GTP-binding proteins in the cytosol of insulin-secreting cells are complexed to GDP dissociation inhibitor proteins. J. Biol. Chem. 267, 17512-17519.

Rexach, M. F. and Schekman, R. W. (1991). Distinc biochemical requirements for the budding, targeting, and fusion of ER-derived transport vesicles. J. Cell Biol. 114, 219-229.

Robbi, M. and Beaufay, H. (1991). The COOH terminus of several liver carboxylesterases targets these enzymes to the lumen of the endoplasmic reticulum. J. Biol. Chem. 266, 20498-20503.

Robinson, M. S. and Kreis, T. E. (1992). Recruitment of coat proteins onto Golgi membranes in intact an permeabilized cells: Effects of brefeldin A and G protein activators. Cell 69, 129-138.

Rogalski, A. A., Bergman, J. E. and Singer, S. J. (1984). Effect of microtubule assembly status on the intracellular processing and surface expression of an integral protein of the plasma membrane. J. Cell Biol. 99, 1101-1109.

Rothberg, K. G., Heuser, J. E., Donzell, W. C., Ying, Y., Glenney, J. R. and Anderson, R. G. W. (1992). Caveolin, a protein component of caveolae membrane coats. Cell 68, 673-682.

Rothman, J. E., Urbani, L. J. and Brands, R. (1984). Transport of protein between cytoplasmic membranes of fused cells: correspondence to processes reconstituted in a cell-free system. J. Cell Biol. 99, 248-259.

Rothman, J. E. and Orci, L. (1992). Molecular dissection of the secretory pathway. Nature 355, 409-415.

Russo, R. N., Shaper, N. L., Taatjes, D. J. and Shaper, J. H. (1992). B-1, 4Galactosyltransferase: A short $\mathrm{NH}_{2}$-terminal fragment that includes the cytoplasmic and transmembrane domain is sufficient for Golgi retention. $J$. Biol. Chem. 267, 9241-9247.

Salminen, A. and Novick, P. J. (1987). A ras-like protein is required for a postGolgi event in yeast secretion. Cell 49, 527-538.

Saraste, J. and Kuismanen, E. (1984). Pre- and post-Golgi vacuoles operate in the transport of Semliki forest virus membrane glycoproteins to the cell surface. Cell 38, 535-549.

Saraste, J. and Kuismanen, E. (1992). Pathways of protein sorting and membrane traffic between the rough endoplasmic reticulum and the Golgi complex. Semin. Cell Biol. 3, 343-355.

Sasaki, T., Kaibuchi, K., Kabcenell, A. K., Novick, P. J. and Takai, Y. (1991). A mammalian inhibitory GDP/GTP exchange protein (GDP dissociation inhibitor) for smg p25A is active on the yeast SEC4 protein. Mol. Cell. Biol. 11, 2909-2912.

Scheel, J. and Kreis, T. E. (1991). Motor protein independent binding of endocytic carrier vesicles to microtubules in vitro. J. Biol. Chem. 266, 1814118148.

Schnapp, B. J. and Reese, T. S. (1989). Dynein is the motor for retrograde axonal transport of organelles. Proc. Nat. Acad. Sci. USA 86, 1548-1552.

Schroer, T. A., Steuer, E. R. and Sheetz, M. P. (1989). Cytoplasmic dynein is a minus end-directed motor for membranous organelles. Cell 56, 937946.

Schwaninger, R., Beckers, C. J. M. and Balch W. E. (1991). Sequential transport of protein between the endoplasmic reticulum and successive Golgi compartments in semi-intact cells. J. Biol. Chem. 266, 13055-13063.

Schwaninger, R., Plutner, H., Bokoch, G. M. and Blach, W. E. (1992). Multiple GTP-binding proteins regulate vesicular transport from the ER to Golgi membranes. J. Cell Biol. 119, 1077-1096.

Segev, N. (1991). Mediation of the attachment or fusion step in vesicular transport by the GTP-binding Ypt1 protein. Science 252, 1553-1556.

Segev, N., Mulholland, J. and Botstein, D. (1988). The yeast GTP-binding YPT1 protein and a mammalian counterpart are associated with the secretion machinery. Cell 52, 915-924.

Semenza, J. C., Hardwick, K. G., Dean, N. and Pelham, H. R. B. (1990). ERD2, a yeast gene required for the receptor-mediated retrieval of luminal ER proteins from the secretory pathway. Cell 61, 1349-1357.

Serafini, T., Orci, L., Amherdt, M. Brunner, M. Khan, R. A. and Rothman, J. E. (1991a). ADP-ribosylation factor is a subunit of the coat of Golgiderived COP-coated vesicles: a novel role for a GTP-binding protein. Cell 67, 239-253.

Serafini, T., Stenbeck, G., Brecht, A., Lottspeich, F., Orci, L., Rothman, J. E. and Wieland, F. T. (1991b). A coat subunit of Golgi derived nonclathrin-coated vesicles with homology to the clathrin coated vesicle coat protein $\beta$-adaptin. Nature 349, 215-220.

Shirataki, H., Kaibuchi, K., Yamaguchi, T., Wada, K., Horiuchi, H. and Takai, Y. (1992). A possible target protein for smg-25A/rab3A small GTPbinding protein. J. Biol. Chem. 267, 10946-10949.

Shirataki, H., Kaibuchi, K., Sakoda, T., Kishida, S., Yamaguchi, T., Wada, K., Miyazaki, M. and Takai, Y. (1993). Rabphilin-3A, a putative target protein for smg $\mathrm{p} 25 \mathrm{~A} / \mathrm{rab} 3 \mathrm{~A}$ p25 small GTP-binding protein related to synaptotagmin. Mol. Cell. Biol. 13, 2061-2068.

Simons, K. and Wandinger-Ness, A. (1990). Polarized sorting in epithelia. Cell 62, 207-210.

Sitia, R. and Meldolesi, J. (1992). Endoplasmic reticulum: a dynamic patchwork of specialized subregions. Mol. Biol. Cell 3, 1067-1072.

Smythe, E., Carter, L. L. and Schmid, S. L. (1992). Cytosol- and clathrindependent stimulation of endocytosis in vitro by purified adaptors. J. Cell Biol. 119, 1163-1171.

Söllner, T., Whiteheart, S. W., Brunner, M., Erdjument-Bromage, H., Geromanos, S., Tempst, P. and Rothman, J. E. (1993). SNAP receptors implicated in vesicle targeting and fusion. Nature 362, 318-324. 
Sossin, W. S., Fisher, J. M. and Scheller, R. H. (1990). Sorting within the regulated secretory pathway occurs in the trans-Golgi network. J. Cell Biol. 110, $1-12$.

Steinman, R. M., Mellman, I., Muller, W. A. and Cohn, Z. A. (1983) Endocytosis and the recycling of plasma membrane. J. Cell Biol. 96, 1-27.

Stutchfield, J. and Cockcroft, S. (1988). Guanine nucleotides stimulate polyphosphoinositide phosphodiesterase and exocytotic secretion from HL60 cells permeabilized with streptolysin O. Biochem. J. 250, 375-382.

Swanson, J., Bushnell, A. and Silverstein, S. C. (1987). Tubular lysosome morphology and distribution within macrophages depend on the integrity of cytoplasmic microtubules. Proc. Nat. Acad. Sci. USA 84, 1921-1925.

Sztul, E. S., Melançon, P. and Howell, K. E. (1992). Targeting and fusion in vesicular transport. Trends Cell Biol. 2, 381-386.

Taylor, T. C., Kahn, R. A. and Melançon, P. (1992). Two distinct members of the ADP-ribosylation factor family of GTP-binding proteins regulate cellfree intra-Golgi transport. Cell 70, 69-79.

Teasdale, R. D., D'Agostaro, G. and Gleeson, P. A. (1992). The signal for Golgi retention of bovine $\beta 1$, 4-galactosyltransferase is in the transmembrane domain. J. Biol. Chem. 267, 4084-4096.

Tooze, S. A. and Huttner, W. B. (1990). Cell-free protein sorting to the regulated and constitutive secretory pathways. Cell 60, 837-847.

Tooze, S. A., Weiss, U. and Huttner, W. B. (1990). Requirement for GTP hydrolysis in the formation of secretory vesicles. Nature 347, 207-208.

Tooze, J. and Hollinshead, M. (1992). In AtT20 and HeLa cells brefeldin A induces the fusion of tubular endosomes and changes their distribution and some of their endocytic properties. J. Cell Biol. 118, 813-830.

Valtersson, C., Dutton, A. H. and Singer, S. J. (1990). Transfer of secretory proteins from the endoplasmic reticulum to the Golgi apparatus: discrimination between homologous and heterologous transfer in intact heterokaryons. Proc. Nat. Acad. Sci. USA 87, 8175-8179.

Van der Sluijs, P., Hull, M., Zahraoui, A., Tavitian, A., Goud, B. and Mellman, I. (1991). The small GTP-binding protein rab4 is associated with early endosomes. Proc. Nat. Acad. Sci. USA 88, 6313-6317.
Warren, G. (1990). Salvage receptors: two of a kind? Cell 62, 1-2.

Waters, M. G., Serafini, T. and Rothman, J. E. (1991). 'Coatomer': a cytosolic protein complex containing subunits of non-clathrin-coated Golgi transport vesicles. Nature 349, 248-251.

Watson, M. L. (1955). The nuclear envelope. Its structure and relation to cytoplasmic membranes. J. Biophys. Biochem. Cytol. 1, 257-270.

Wattenberg, B. W. (1990). The molecular control of transport vesicle fusion. New Biol. 2, 505-511.

Wattenberg, B. W., Hiebsch, R. R., LeCureux, L. W. and White, M. P. (1990). Identification of a $25 \mathrm{kD}$ protein from yeast cytosol that operates in a prefusion step of vesicular transport between compartmets of the Golgi. $J$. Cell Biol. 110, 947-954.

Weidman, P., Roth, R. and Heuser, J. (1993). Golgi membrane dynamics imaged by freeze-etch electron microscopy: views of different membrane coatings involved in tubulation versus vesiculation. Cell 75, 123-133.

Wessling-Resnick, M. and Braell, W. A. (1990). Characterization of the mechanism of endocytic vesicle fusion in vitro. J. Biol. Chem. 265, 1675116759.

White, J. M. (1992). Membrane fusion. Science 258, 917-924.

Wieland, F. T., Gleason, M. L., Serafini, T. and Rothman, J. E. (1987). The rate of bulk flow from the endoplasmic reticulum to the cell surface. Cell $\mathbf{5 0}$ 289-300.

Wilson, D. W., Whiteheart, S. W., Wiedmann, M., Brunner, M. and Rothman, J. E. (1992). A multisubunit particle implicated in membrane fusion. J. Cell Biol. 117, 531-538.

Wong, D. H. and Brodsky, F. M. (1992). 100-kD proteins of Golgi- and transGolgi network-associated coated vesicles have related but distinct membrane binding properties. J. Cell Biol. 117, 1171-1179.

Wood, S. A., Park, J. E. and Brown, W. J. (1991). Brefeldin A causes a microtubule-mediated fusion of the trans-Golgi network and early endosomes. Cell 67, 591-600. 